\title{
Dose-Dependent Effect of Smoking on Fertility Status among Men in Gaza Strip, Palestine
}

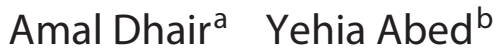 \\ aDepartment of Health, UNRWA, Rafah, Palestine; baculty of Public Heath, Al-Quds University, Al-Bireh, Palestine
}

\section{Keywords}

Primary infertility · Tobacco smoking · Men · Gaza strip · Palestine

\begin{abstract}
Introduction: Tobacco smoking is constantly increasing mainly in developing countries and accounts for many morbidities and mortalities. Several studies have addressed the effect of smoking on male reproductive mechanism, particularly semen quality, but the effect of smoking behavior remained inconclusive. The aim of this study was to explore the relationship of tobacco smoking status, intensity, and duration between infertile and fertile men and other accompanying genitourinary conditions. Methods: Through a case-control study, 160 infertile couples were recruited from in vitro fertilization centers in Gaza Strip. Correspondingly, another 160 fertile couples were selected from governmental clinics and residentially matched with cases. The probable stratified random technique for 2017/2018 patient's registries was performed. Both cases and controls were interviewed with a selfconstructed questionnaire. Descriptive analysis, logistic regression, and the Cochran-Mantel-Haenszel test were deployed statistically with a significant level set on $p=0.05$. Results: The mean age of cases and controls was $35.7 \pm 10$ and $34.9 \pm 5$ years, respectively, where 70 and $59 \%$, respec-
\end{abstract}

tively, were refugees; 52 and 43\%, respectively, had university education; and $10.6 \%$ compared to $5.6 \%$, respectively, earn > USD 720/month. Active smoking was detected among $38 \%$ of infertile men and $42.5 \%$ of fertile men. Nevertheless, passive smoking (52.5\% infertile and $37.5 \%$ fertile) and smoking duration $>2$ years ( $85.2 \%$ infertile and $69.1 \%$ fertile) showed a positive significant relationship $(p=0.007$ and $p=$ 0.030 , respectively). Furthermore, 34 and $49 \%$ of all infertile smokers showed a dose-dependent effect (odds ratio [OR]: $2.98, p=0.023$ for $6-10 \mathrm{cig} /$ day and OR: 3.68, $p=0.004$ for $>10$ cig/day), mainly in nonobstructive causes (OR: $4.26, p=0.040$ for $6-10$ cig/day and OR: 5.52, $p=0.004$ for $>10$ cig/day). Varicocele was more likely to occur among passive smokers ( $p=$ $0.024)$, smoking $>10 \mathrm{cig} /$ day $(p=0.038)$, and for $>2$ years $(p=$ 0.024 ). Recurrent genitourinary tract infection was 3 times more among infertile passive smokers (OR: $2.96,95 \%$ confidence interval: $1.38-6.32$, and $p=0.005$ ). Adjustment for age and refugee status showed 3.5 times risk for passive smoking, more than 9 times risk for former smokers, and 2.8 risk when smoking $>5$ cig/day. Conclusion: Smoking more than 5 cigarettes/day and for $>2$ years duration or exposure to passive smoking hold an increased risk on the fertility status of men. More global and national efforts need to be directed to controlling and eliminating tobacco smoking.

C 2021 The Author(s)

Published by S. Karger AG, Basel karger@karger.com www.karger.com/dmj

Karger $\stackrel{\text { ' }}{5}$

GOPEN ACCESS
(C) 2021 The Author(s)

Published by S. Karger AG, Basel

This is an Open Access article licensed under the Creative Commons Attribution-NonCommercial-4.0 International License (CC BY-NC) (http://www.karger.com/Services/OpenAccessLicense), applicable to the online version of the article only. Usage and distribution for commercial purposes requires written permission.
Correspondence to:

Amal Dhair, amaldhair@yahoo.com 


\section{Introduction}

Tobacco smoking is one of the largest global public health problems, which is frankly consumed by over 1.1 billion people around the world. A yearly estimate stated that around 8 million people die from different forms of tobacco exposure. More than 7 million people die yearly from direct tobacco use, while around 1.2 million are the result of second-hand smoking [1]. One in 5 adults in the world smoke tobacco [2], and typically more men (35\% of men globally) than women ( $6 \%$ of women globally) are known as active users [2,3]. The increasing prevalence is most commonly witnessed in the eastern Mediterranean and African Region [4]. The fact that tobacco smoking holds a detrimental effect on health in general [5], and the impact on the male reproductive system has long been a special concern of many scientists and researchers [6].

Inhaled cigarette smoke contains various toxic substances other than nicotine, including carbon monoxide, benzopyrene, naphthalene, meth naphthalene, radioactive polonium, dimethyl benzanthracene, and dimethylnitrosamine, that were suggested to harm the male reproductive system $[7,8]$. Primary infertility is defined clinically in both males and females as the inability to achieve pregnancy for $>1$-year duration of unprotected intercourse [9]. Many different medical conditions and/or risks can be related to fertility problems in men. Infertility problems could be related to more than one cause or factor; others could assume one cause or factor, while some cases are identified as idiopathic [10]. Although most studies discussed the relationship between tobacco smoking and infertility among men in the respect of their semen parameters, some reported contradictory results. A recent meta-analysis concluded that tobacco smoking is associated with lower sperm count and more morphological abnormalities, while the sperm motility, semen $\mathrm{pH}$, and reproductive hormones were not affected [11]. On the other hand, another systemic review and meta-analysis reported that cigarette smoking has an overall negative impact on all semen parameters [12]. Scarce research was found discussing the intensity and duration of smoking along with accompanied genitourinary health conditions and their effect on the fertility status among men, especially those living in Gaza Strip, Palestine. Accordingly, the aim of this study was to explore the relationship of tobacco smoking status, intensity, and duration between infertile and fertile men and other accompanying genitourinary conditions.

Primary Infertility and Smoking among Men

\section{Materials and Methods}

\section{Sampling and Study Participants}

A case-control study design was conducted with the participation of fertile and infertile married couples in Gaza Strip, Palestine. Infertile couples were defined according to the clinical definition of the World Health Organization for primary infertility: inability to achieve pregnancy despite exposure to the risk for 1 year or more of unprotected intercourse [9]. Cases were selected from those that were registered at 5 in vitro fertilization centers for treatment and were chosen from each center through the stratified random sampling technique. Controls were defined as those who achieved at least 2 normal pregnancies with no history of any means of assistive reproductive techniques. They were matched with the cases according to their residential area. As a population setting, controls were chosen from governmental primary healthcare centers, by tracing couples who were married and receiving antenatal care, postnatal care, or family planning services and who were congruent with the predetermined criteria. Sample size was calculated through Epi-info 7 calculator with a two-sided confidence interval (CI) of $95 \%$, power of study of $80 \%$, percentage of exposed controls of $50 \%$ (because information about the risk of exposure among the control group was limited), odds ratio (OR) of 2 , and ratio of cases to controls of 1 . The final sample size was 320 total study populations.

\section{Study Instrument and Data Collection}

The researchers developed and self-constructed a face-to-face interview questionnaire that fully achieved the study objectives and was typically suitable for the study population context. We were committed to acquire an informed consent form prior to each participation. The consent form explained the aim of the study and the expected benefits of the research along with emphasizing that confidentiality is highly implemented and that taking part in the study is voluntary with their right to withdraw participation at any time. An ethical approval was obtained from the Palestinian Health Research Council and an administrative approval was acquired from the Al-Quds University.

Data collection was performed through 2 nurses with highqualified medical and practical background. They were chosen upon having adequate expertise in the research field. Prior to data collection, the data collectors had a comprehensive training on the structure of the instrument and the data collection process to minimize interobserver variation and eventually ensure research reliability. An iterative pilot study as a cognitive qualitative testing was performed on $10 \%$ of total sample size, and appropriate minimum modification on the instrument was applied.

\section{Statistical Analysis}

Analysis was conducted through IBM SPSS Statistics 24 package. Data were cleaned and coded where appropriate. Descriptive analysis was deployed to produce crude distribution of variables (percentage and frequency), and further bivariate analysis was performed to calculate the OR through the $\chi^{2}$ cross-tabulation. This procedure was used for the demographic variables, to calculate the risk of active smoking, passive smoking, former smoking, smoking intensity, and smoking duration of selected subjects. Also, it was used to show the risk of smoking among different causes of infertility (Fisher Exact test) and different accompanied genitourinary conditions (Cochran-Mantel-Haenszel test). Finally, to examine 
Table 1. General characteristics of the study population

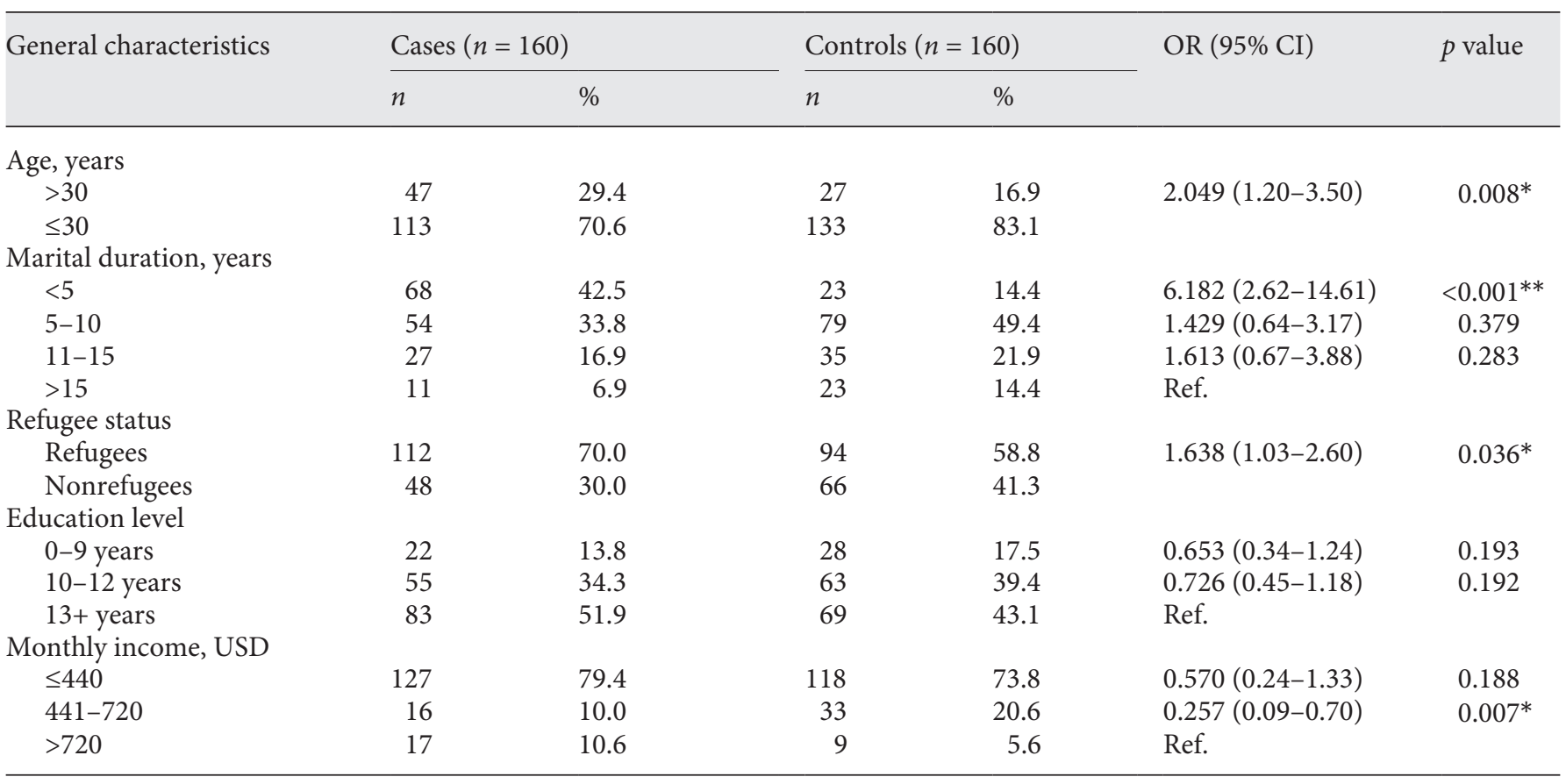

OR, odds ratio; CI, confidence interval. ${ }^{*}$ Significant level $p=0.05 .{ }^{* *}$ Highly significant level $p<0.001$. Ref., reference used to breakdown $>2 \times 2$ contingency table.

the size of change in the risk between statistically significant independent variables and tobacco smoking, we used binary logistic regression analysis with the best fit module. The statistically significant level was set as $p<0.05$.

\section{Results}

Table 1 shows the general characteristics of the study population. From a total of 160 infertile men, 47 (29.4\%) were more than 30 years age than 27 (16.9\%) fertile men $(p=0.008)$. Marital duration of $>5$ years was reported among $68(42.5 \%)$ infertile men, compared to only 23 (14.4\%) of their counterpart. More than two-thirds of the infertile group $(70 \%)$ were Palestinian refugees $(p=$ 0.036). Almost half of them (51.9\%) had a university degree compared to $43.1 \%$ of the fertile ones, with nearly the same distribution being noticed among those who completed $10-12$ years of schooling ( 34.3 and $39.4 \%$, respectively) and those who gained $<10$ years ( 13.8 and $17.5 \%$, respectively). The controls were double the cases when comparing a monthly income of USD 441-720 for both groups ( $p=0.007$ ); otherwise the same distribution was noticed among those who gain less than USD 440 a month.
Table 2 demonstrates the smoking status, intensity, and duration in both groups. Results showed that nearly half the infertile men were exposed to passive smoking compared to only $37.5 \%$ of the fertile group $(p=0.007)$. Former smokers were more among infertile men (37\%) than fertile ones $(27.5 \%)$, but the relationship did not reach a statistically significant level. Frequency of active smokers among infertile men (38\%) was less than those in the fertile group (42.5\%), but the smoking intensity among the 2 groups showed a dose-dependent effect when smoking 6-10 cigarettes per day (OR: 2.98 and $p=$ 0.023 ) and more than 10 cigarettes per day (OR: 3.68 and $p=0.004)$. Furthermore, smoking for more than 2 years was 2.5 times more likely among the infertile group $(p=$ $0.03)$.

Table 3 presents the distribution of tobacco smoking variables by causes of infertility among men. Passive smoking was detected more among infertile men with nonobstructive causes (OR: 1.7, 95\% CI: 1.05-2.88, and $p=0.032$ ) and those with obstructive causes (OR: 5.0, 95\% CI: $1.30-19.20$, and $p=0.014)$ than fertile men. Furthermore, a positive dose-dependent association was observed among smokers with nonobstructive causes. The coefficient increased gradually from 4.263 for 6-10 ciga- 
Table 2. Distribution of study population by tobacco smoking status, intensity, and duration

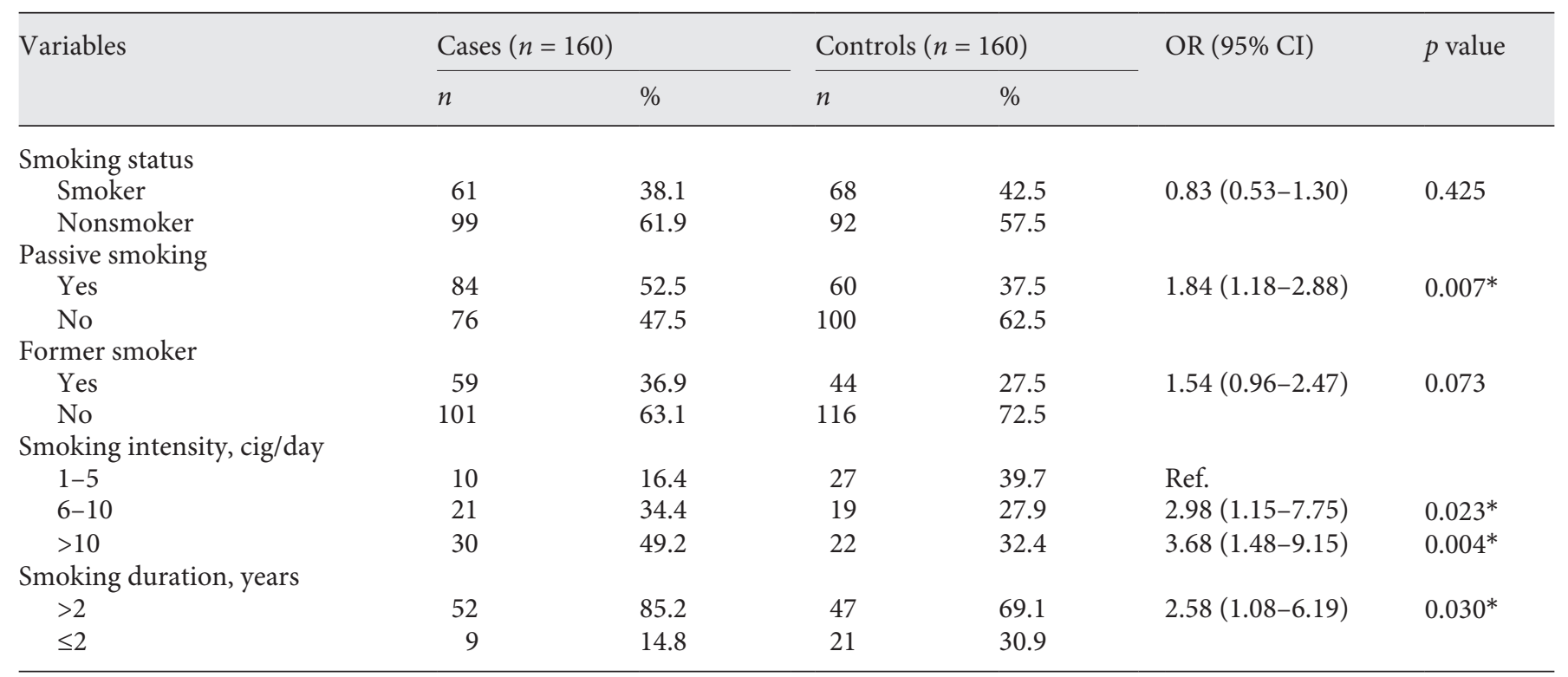

OR, odds ratio; CI, confidence interval. * Significant level $p=0.05$. Ref., reference used to breakdown $>2 \times 2$ contingency table; cig/ day, cigarettes per day.

Table 3. Distribution of study population by causes of infertility and tobacco smoking

\begin{tabular}{|c|c|c|c|c|c|c|c|c|c|c|}
\hline & $\begin{array}{l}\text { Control } \\
n=160\end{array}$ & $\begin{array}{l}\text { Non- } \\
\text { obstructive } \\
n=100\end{array}$ & OR & $p$ value & $\begin{array}{l}\text { Obstructive } \\
n=12\end{array}$ & OR & $p$ value & $\begin{array}{l}\text { Idiopathic } \\
n=32\end{array}$ & OR & $p$ value \\
\hline Yes & 60 & 51 & 1.735 & $0.032 *$ & 9 & 5.0 & $0.014^{\mathbb{P}, *}$ & 12 & 1.00 & 1.00 \\
\hline No & 100 & 49 & & & 3 & & & 20 & & \\
\hline $6-10$ & 19 & 12 & 4.263 & $0.040^{\mathbb{P}, *}$ & 1 & 0.710 & $1^{\mathbb{P}}$ & 5 & 7.105 & $0.084^{\mathbb{P}}$ \\
\hline$>10$ & 22 & 18 & 5.523 & $0.004^{\mathbb{P}, *}$ & 1 & 0.614 & $1^{\mathbb{P}}$ & 6 & 7.364 & $0.101^{\mathbb{P}}$ \\
\hline \multicolumn{11}{|c|}{ Duration of smoking, years } \\
\hline$>2$ & 47 & 30 & 3.351 & $0.049^{\mathbb{P}, *}$ & 2 & 0.447 & $0.588^{\mathbb{P}}$ & 9 & 1.340 & $1^{\mathbb{P}}$ \\
\hline$\leq 2$ & 21 & 4 & & & 2 & & & 3 & & \\
\hline
\end{tabular}

OR, odds ratio; cig/day, cigarettes per day. ${ }^{\mathbb{P}}$ Fischer Exact test. ${ }^{*}$ Significant level $p=0.05$. Ref., reference used to breakdown $>2 \times 2$ contingency table.

rettes/day to 5.523 for $>10$ cigarettes/day. Idiopathic causes showed no relationship with all forms of smoking behavior except for passive smoking $(p=0.014)$.

Table 4 presents the distribution of tobacco smoking variables by accompanying genitourinary conditions among the study population. The genitourinary conditions included were unilateral or bilateral varicocele and recurrent genitourinary infection $(>5$ times in the past 2 years). Passive smoking ( $p=0.024)$, smoking more than 5 cigarettes per day ( $p=0.038$ for $6-10$ and $p=0.035$ for $>10 \mathrm{cig} /$ day), and smoking for $>2$ years ( $p=0.024)$ were more among infertile men with unilateral or bilateral varicocele. Passive smoking was also significantly higher among infertile men with recurrent 
Table 4. Relationship between tobacco smoking and various genitourinary conditions in infertile and fertile men (Cochran-MantelHaenszel test)

\begin{tabular}{|c|c|c|c|c|c|c|c|c|}
\hline & \multicolumn{2}{|c|}{ Unilateral/bilateral varicocele } & OR & $p$ value & \multicolumn{2}{|c|}{ Recurrent genitourinary infection } & OR & $p$ value \\
\hline \multicolumn{9}{|c|}{ Passive smoking } \\
\hline Yes & 41 & 5 & 3.42 & $0.024^{*}$ & 35 & 18 & 2.96 & $0.005^{*}$ \\
\hline No & 36 & 15 & & & 25 & 38 & & \\
\hline $6-10$ & 7 & 1 & 21.0 & $0.038^{\mathbb{P}, *}$ & 7 & 3 & 9.33 & $0.028^{\mathbb{P}, *}$ \\
\hline$>10$ & 20 & 6 & 10.0 & $0.035^{\mathbb{P}, *}$ & 17 & 16 & 4.25 & $0.082^{\mathbb{P}}$ \\
\hline \multicolumn{9}{|c|}{ Duration of smoking, years } \\
\hline$>2$ & 24 & 5 & 6.0 & $0.024^{\mathbb{P}, *}$ & 20 & 18 & 1.67 & 0.412 \\
\hline$\leq 2$ & 4 & 5 & & & 6 & 9 & & \\
\hline
\end{tabular}

OR, odds ratio; cig/day, cigarettes per day. ${ }^{*}$ Significant level $p=0.05 .{ }^{\mathbb{P}}$ Mantel-Haenszel 2-tailed $p$ value. Ref., reference used to breakdown $>2 \times 2$ contingency table.

Table 5. Predictors of primary infertility among independent tobacco smoking variables (binary logistic regression)

\begin{tabular}{llll}
\hline Independent variables & OR & $95 \%$ CI & $p$ value \\
\hline $\begin{array}{l}\text { Age } \quad \text { Continuous } \\
\text { Refugee status } \\
\quad \text { Nonrefugee = reference }\end{array}$ & 1.003 & $0.960-1.048$ & 0.894 \\
$\begin{array}{l}\text { Passive smoking } \\
\quad \text { No }=\text { reference }\end{array}$ & 1.260 & $0.541-2.935$ & 0.592 \\
$\begin{array}{l}\text { Former smoker } \\
\quad \text { No }=\text { reference }\end{array}$ & 9.455 & $1.491-8.009$ & $0.004^{*}$ \\
$\begin{array}{l}\text { Smoking intensity } \\
\quad \leq 5 \text { cigarettes/day }=\text { reference }\end{array}$ & 2.788 & $1.080-7.197$ & $0.034^{*}$ \\
$\begin{array}{l}\text { Smoking duration } \\
\quad \leq 2 \text { years = reference }\end{array}$ & 2.324 & $0.810-6.669$ & 0.117 \\
\begin{tabular}{l} 
Constant \\
\hline
\end{tabular} & 0.015 & & $<0.001^{* *}$ \\
\hline
\end{tabular}

OR, odds ratio; CI, confidence interval. Model coefficient $\chi^{2}=23.84 ; p=0.001$; Nagelkerke $r^{2}=0.225$; membership for cases. ${ }^{*}$ Significant at $p<0.05$. ${ }^{* *}$ Highly significant at $p<0.001$. genitourinary infection than fertile men with the same condition $(p=0.005)$.

Table 5 illustrates binary logistic regression of the positively associated independent variables with primary infertility in men. After adjustment for age and refugee status, passive smoking was $>3$ times more likely among infertile men than their counterpart $(p=0.004)$; former smokers held $>9$ times risk $(p<0.001)$, and smoking more than 5 cigarettes per day was more than twice among infertile men $(p=0.034)$.

\section{Discussion/Conclusion}

In this study, we evaluated the relationship between tobacco smoking in both men with normal fertility status and men suffering from primary infertility. The study revealed that passive smoking among all participants is way more among infertile (52.5\%) than fertile men (37.5\%) $(p=0.007)$. Passive smoking occurs when an individual inhales the smoke that is produced from the burning end of the cigarette (sidestream smoke), which represents 
$90 \%$ of the smoke in the area surrounding the smoker and another $10 \%$ produced from the exhaled smoke (mainstream smoke) [13]. According to a biomarker that detects exposure to tobacco smoke, around $50 \%$ of nonsmokers are passive smokers [14]. Usually, passive smokers exhale large amounts of superoxide and hydrogen peroxide [13] that form most of the sidestream smoke and that affect sperm motility [15-17], sperm chromatin integrity [18], and that may result in impaired oocyte fertilization [19].

Being a case-control study that had recruited infertile couples from fertility centers and who were under some sort of medical consultation, investigation, or even management for their infertility problem, many men were already enduring lifestyle modification as a preliminary management plan like losing excess weight and cessation of smoking. In addition, some men might have voluntarily stopped any unhealthy habits for the sake of childbearing which might have also included quitting of smoking. These suggestions may explain the decreased frequency of active smokers among infertile men in relation to their counterpart in relation to former smokers. Moreover, exploring the intensity of tobacco use per day revealed a dose-response effect among infertile men. Several research studies confirmed the reverse dose-dependent effect between the amount of cigarette consumption and semen parameters in men [20-22]. In a large crosssectional study that included 2,542 men, Ramlau-Hansen et al. [20] conducted 7 semen quality studies to evaluate the association between current smoking and semen quality. Researchers observed a reverse dose-dependent association between smoking and total sperm count, semen volume, and the number of motile sperms. However, the study reported that ever-smokers had values of total sperm count and sperm concentration in between neversmokers and currently smoking men, suggesting a partly irreversible effect of tobacco smoking. However, prospective studies with appropriate controls need to be conducted to rule out reversibility from otherwise.

After adjustment for age and refugee status, our study revealed that men who were exposed to passive smoking were about 3.5 times more likely to have primary infertility, former smokers had 9 times the risk, and men who smoke $>5$ cigarettes per day had twice the risk. When some researchers found that smoking is associated with both reduced sperm quality and idiopathic infertility [23, 24], particularly in heavy long-term smokers $[25,26]$, some research studies suggested no relationship exists [27-29]. Possible explanations for such opposing and confusing results could be related to the different metric

Primary Infertility and Smoking among Men measures used and the difficulty in adjusting confounding factors that could be existing such as chronic medical diseases, passive smoking, environmental toxins, and socioeconomic status [8].

In our study, causes of infertility among men recruited for the study were categorized into 3 types as follows: nonobstructive causes, obstructive causes, and idiopathic etiology. Nonobstructive causes included abnormal spermatogenesis, antisperm antibodies, low sperm motility, high semen viscosity, varicocele, oligospermia, azoospermia, necrospermia, and necrozoospermia. Obstructive causes were found to include ejaculatory disorders, epididymal obstruction, prostatic enlargement, obstructive oligospermia, and obstructive azoospermia. Analysis revealed another positive dose-dependent relationship between infertile men with nonobstructive causes and fertile men in relation to the number of cigarettes consumed per day. The coefficient increased from 4.26 (95\% CI: 1.19-15.25) among 6-10 cigarettes/day consumers to 5.52 (95\% CI: 1.63-18.72) among > 10 cigarettes/day consumers. This can confirm what has been discussed before about the effect of tobacco smoking on semen parameters and its direct relationship with infertility among men. However, a recent systemic review and meta-analysis that was conducted with 10,823 infertile men found that oligospermia was significantly higher among infertile smokers, while teratospermia, azoospermia, and asthenospermia did not show a significant relationship. Reproductive-related hormones: testosterone, prolactin, and follicular stimulating hormone were found not related to tobacco smoking [11]. The possible explanation that might be involved in such changes in semen parameters is the harmful effect of the cigarette's toxic components on male reproduction germ cells and their developmental process [30].

For intense scrutinizing, the effect of tobacco smoking on the fertility status of men and accompanying genitourinary conditions were compared within the 2 groups. Based on our results, unilateral or bilateral varicocele seemed to be more likely to occur among passive smokers, those who smoke $>5$ cigarettes per day, and those who remained active smokers for $>2$ years. Research studies suggested that oligospermia incidence among smokers with varicocele is ten times greater than among nonsmokers. This could be explained by the increased secretion of adrenal catecholamines, influenced by the nicotine component of cigarettes, which in turn leads to seminiferous tubule damage due to the retrograde flow of these hormones through the varicosed internal spermatic vein [31]. Others suggested that oxidative stress inducing 
a significantly higher level of plasma protein carbonyls in spermatic veins among smokers with varicocele than nonsmoker varicocele patients is a significant marker [32]. Moreover, our findings revealed that genitourinary tract infection of $>5$ times in the past 2 years was more among passive smokers and among those who smoke $>5$ cigarettes per day. However, the role of tobacco smoking on the renal system has not been extensively reviewed. In 1 case-control study, smokers were found more likely to suffer from nephrolithiasis than nonsmokers (OR: 2.06, 95\% CI: 1.06-4.01, and $p=0.03$ ) [33], but other hospitalbased study found that the relationship was weak to be identified as a risk factor [34], although some suggested that tobacco smoking decreases urinary output and aggravate oxidative stress which in turn are related to nephrolithiasis $[35,36]$.

In conclusion, studying smoking status alone in men is not typically indicative to pursue the hazardous effect of tobacco on the male reproductive state. Exploring passive smoking, former smoking, the cumulative effect of tobacco consumption examined through the amount of use per day, and the duration of being an active smoker provided substantially indicative findings. From the attained results, global tobacco control efforts need to outline the specific hazards of tobacco smoking on health in general and on the reproduction system in particular.

\section{Acknowledgements}

We would like to thank all male participants who kindly contributed to the establishment of this work. Sincere gratitude is conveyed to managers of the in vitro fertilization centers for support and immense efforts.

\section{Statement of Ethics}

The study followed the Declaration of Helsinki and the ethical approval was obtained from the Palestinian Health Research Council in Gaza Strip, Number PHRC/HC/548/19 Dated 2019/04/09 before conducting the study. All participants signed a written informed consent that was attached to each questionnaire to participate in this study.

\section{Conflict of Interest Statement}

The authors have no conflicts of interest to declare.

\section{Funding Sources}

No funding was received for this work.

\section{Author Contributions}

A.D. developed the concept and the design of the work, prepared the study proposal with hypothesis statements and research questions, performed data entry, statistical analysis, and results interpretation. Y.A. critically reviewed and substantially advised on the methodology and statistical analysis, assisted in results analysis and interpretation, and supervised the whole study. A.D. wrote the manuscript, and Y.A. provided feedback and helped shape the analysis and the manuscript. Both the authors reviewed and agreed on the final version of the manuscript.

\section{Availability of Data and Material}

The data that support the findings of this study are openly available in "figshare" at 10.6084/m9.figshare.14628474 [37].

\section{References}

1 World Health Organization. Tobacco: key facts: leading cause of death, illness and impoverishment [Internet]. WHO; 2020 [cited 2020 Jun 11]. Available from: https://www.who.int/ news-room/fact-sheets/detail/tobacco.

2 Hannah R, Max R. Smoking [Internet]. Our World in Data; 2019 [cited 2020 Jun 12]. Available from: https://ourworldindata.org/ smoking\#share-who-smoke.

3 Jha P, Peto R. Global effects of smoking, of quitting, and of taxing tobacco. N Engl J Med. 2014;370(1):60-8.

4 World Health Organization. World Health Statistics data visualizations dashboard: tobacco smoking [Internet]. World Health Organization; 2015 [cited 2020 Jun 12]. Available from: https://apps.who.int/gho/data/ node.sdg.3-a-viz?lang=en.
5 Office of the Surgeon General (US). The health consequences of smoking: a report of the surgeon general. Centers for Disease Control and Prevention (US); 2004. 51576 p. Report No. NBK44695.

6 Dai JB, Wang ZX, Qiao ZD. The hazardous effects of tobacco smoking on male fertility. Asian J Androl. 2015 Nov 1;17(6):954-60.

7 Kim HY, Ko EB, Yang WM, Kim HY, Chang MS, Park SK. Negative effect of nicotine on male reproductive system in mouse. Fertil Sterility. 2008 Sep 1;90:S189.

8 Harlev A, Agarwal A, Gunes SO, Shetty A, du Plessis SS. Smoking and male infertility: an evidence-based review. World J Mens Health. 2015;33(3):143
9 World Health Organization. WHO: Infertility definitions and terminology [Internet]. World Health Organization; 2016 [cited 2019 Mar 19]. Available from: https://www.who. int/reproductivehealth/topics/infertility/definitions/en/.

10 The Official Foundation of the Americal Urological Association. Male infertility: symptoms, diagnosis \& treatment [Internet]. Urology Care Foundation; 2019 [cited 2020 Jun 13]. Available from: https://www.urologyhealth.org/urologic-conditions/male-infertility.

11 Bundhun PK, Janoo G, Bhurtu A, Teeluck AR, Soogund MZS, Pursun M, et al. Tobacco smoking and semen quality in infertile males: a systematic review and meta-analysis. BMC Public Health. 2019;19(1):36. 
12 Sharma R, Harlev A, Agarwal A, Esteves SC. Cigarette smoking and semen quality: a new meta-analysis examining the effect of the 2010 World Health Organization laboratory methods for the examination of human semen. Eur Urol. 2016;70(4):635-45.

13 Birru RL, Di YP. Pathogenic mechanism of second hand smoke induced inflammation and COPD. Front Physiol. 2012;3:348.

14 Pirkle JL, Bernert JT, Caudill SP, Sosnoff CS, Pechacek TF. Trends in the exposure of nonsmokers in the U.S. population to secondhand smoke: 1988-2002. Environ Health Perspect. 2006;114(6):853-8.

15 El-Taieb MA, Herwig R, Nada EA, Greilberger J, Marberger M. Oxidative stress and epididymal sperm transport, motility and morphological defects. Eur J Obstet Gynecol Reprod Biol. 2009;144(Suppl 1):S199-203.

16 Kao SH, Chao HT, Chen HW, Hwang TIS, Liao TL, Wei YH. Increase of oxidative stress in human sperm with lower motility. Fertil Steril. 2008;89(5):1183-90.

17 Benedetti S, Tagliamonte MC, Catalani S, Primiterra M, Canestrari F, De Stefani S, et al. Differences in blood and semen oxidative status in fertile and infertile men, and their relationship with sperm quality. Reprod Biomed Online. 2012;25(3):300-6.

18 Tello-Mora P, Hernández-Cadena L, Pedraza J, López-Bayghen E, Quintanilla-Vega B. Acrosome reaction and chromatin integrity as additional parameters of semen analysis to predict fertilization and blastocyst rates. Reprod Biol Endocrinol. 2018;16(1):102.
19 Shamsi MB, Venkatesh S, Kumar R, Gupta NP, Malhotra N, Singh N, et al. Antioxidant levels in blood and seminal plasma and their impact on sperm parameters in infertile men. Indian J Biochem Biophys. 2010 Feb;47(1): 38-43.

20 Ramlau-Hansen $\mathrm{CH}$, Thulstrup AM, Aggerholm AS, Jensen MS, Toft G, Bonde JP. Is smoking a risk factor for decreased semen quality? A cross-sectional analysis. Hum Reprod. 2007;22(1):188-96.

21 Hassan MA, Killick SR. Negative lifestyle is associated with a significant reduction in fecundity. Fertil Steril. 2004;81(2):384-92.

22 Kovac JR, Khanna A, Lipshultz LI. The effects of cigarette smoking on male fertility. Postgrad Med. 2015;127(3):338-41.

23 Colagar AH, Jorsaraee GA, Marzony ET. Cigarette smoking and the risk of male infertility. Pak J Biol Sci. 2007;10(21):3870-4.

24 Künzle R, Mueller MD, Hänggi W, Birkhäuser $\mathrm{MH}$, Drescher $\mathrm{H}$, Bersinger NA. Semen quality of male smokers and nonsmokers in infertile couples. Fertil Steril. 2003 Feb 1; 79(2):287-91.

25 Mahboubi M, Foroughi F, Ghahramani F, Shahandeh H, Moradi S, Shirzadian T. A casecontrol study of the factors affecting male infertility. Turk J Med Sci. 2014;44(5):862-5.

26 Tang Q, Pan F, Wu X, Nichols CE, Wang X, $\mathrm{Xia} Y$, et al. Semen quality and cigarette smoking in a cohort of healthy fertile men. Environ Epidemiol. 2019 Aug;3(4):e055.

27 Okonofua F, Menakaya U, Onemu SO, OmoAghoja LO, Bergstrom S. A case-control study of risk factors for male infertility in Nigeria. Asian J Androl. 2005 Dec;7(4):351-61.

28 Lewin A, Gonen O, Orvieto R, Schenker JG Effect of smoking on concentration, motility and zona-free hamster test on human sperm. Arch Androl. 1991;27(1):51-4.
29 Sergerie M, Ouhilal S, Bissonnette F, Brodeur J, Bleau G. Lack of association between smoking and DNA fragmentation in the spermatozoa of normal men. Hum Reprod. 2000;15(6): 1314-21.

30 Zenzes MT. Smoking and reproduction: gene damage to human gametes and embryos. Hum Reprod Update. 2000;6(2):122-31.

31 Klaiber EL, Broverman DM, Pokoly TB, Albert AJ, Howard PJ, Sherer JF. Interrelationships of cigarette smoking, testicular varicoceles, and seminal fluid indexes. Fertil Steril. 1987;47(3):481-6.

32 Chen SS, Chang LS, Wei YH. Oxidative damage to proteins and decrease of antioxidant capacity in patients with varicocele. Free Radic Biol Med. 2001 Jun 1;30(11):1328-34.

33 Tamadon MR, Nassaji M, Ghorbani R. Cigarette smoking and nephrolitiasis in adult individuals. Nephrourol Mon. 2013;5(1):702-5.

34 Słojewski M, Czerny B, Safranow K, Droździk M, Pawlik A, Jakubowska K, et al. Does smoking have any effect on urinary stone composition and the distribution of trace elements in urine and stones? Urol Res. 2009;37(6):31722.

35 Mobley D, Baum N. Smoking: Its impact on urologic health. Rev Urol. 2015;17(4):220.

36 Ozbek E. Induction of oxidative stress in kidney. Int J Nephrol. 2012 [cited 2020 Jun 23]. Available from: https://www.hindawi.com/ journals/ijn/2012/465897/.

37 Dhair A, Abed Y. Smoking 2.sav. figshare. Dataset 2021 